\title{
Security Design of University Campus Landscape Based on BIM
}

\author{
Liyuan Zhao $\mathbb{D}$ \\ Xijing University, Xi'an 710123, Shaanxi, China \\ Correspondence should be addressed to Liyuan Zhao; 20140083@xijing.edu.cn \\ Received 3 January 2022; Revised 19 January 2022; Accepted 20 January 2022; Published 11 February 2022 \\ Academic Editor: Xin Ning \\ Copyright (C) 2022 Liyuan Zhao. This is an open access article distributed under the Creative Commons Attribution License, which \\ permits unrestricted use, distribution, and reproduction in any medium, provided the original work is properly cited. \\ With the dawn of the knowledge economy, China's university campus construction has reached its pinnacle. However, there are \\ numerous issues with the related construction process, such as scale imbalances, architectural style convergence, loss of en- \\ vironmental characteristics, and a lack of spirit of place on many university campuses, all of which eventually lead to in- \\ compatibility between campus architecture and landscape environment, dilution of campus cultural atmosphere, and lack of \\ sustenance for university humanistic spirit. The quality of the campus landscape has become a key criterion for judging the \\ campus environment, as it has a significant impact on the overall environment, image, and quality of the campus. To improve the \\ quality of the campus landscape environment, landscape design must be considered as part of architectural planning and design, \\ and campus architecture and landscape must be integrated. Campus landscape engineering construction has a full life cycle, and \\ construction safety has an impact on the overall situation. To ensure construction safety throughout the life cycle, a solid \\ mathematical model of construction safety management should be established. This paper proposes using Building Information \\ Modeling (BIM) to conduct research on landscape security, starting with the development of university campus landscapes and \\ using mobile edge computing technology.
}

\section{Introduction}

With the accelerating process of urbanization, the scale of construction projects is also expanding, and the construction quality and safety of construction projects have attracted more and more attention [1]. In this context, China's landscape architecture industry has also begun to develop rapidly. Urban green space and scenic spots appear all over the country like spring after rain. Our university campus landscape is also among them, with a wide variety of contents. In terms of attributes, it can generally be divided into gray, green, and blue [2]. Color landscape refers to the artificial objects in the campus, including campus architectural form, architectural decoration, campus roads, public facilities, rest facilities, lighting, municipal facilities, etc. Green landscape refers to the living landscape formed by artificial art treatment with natural forms or natural elements in the campus, including mountains, natural and artificial mountains, green space, and animals and plants in the campus [3]. The term "blue landscape" refers to the campus's water bodies, rivers, lakes, and waterscape. When it comes to architecture, however, the management of its safety is critical. There is aerial work, and the architecture is systematic, complex, and difficult. The architectural scene, particularly campus culture, must be integrated, so the layout of the entire construction has become a qualitycontrol issue for the entire project. Unreasonable structures have resulted in a slew of safety issues across society, including drownings, forest fires, stampede accidents, landslides, and so on. There are a variety of other safety factors that contribute to these issues, including perceptions, environmental factors, facilities, and equipment [4]. Methods: the traditional arrangement and treatment of university campus landscapes are primarily based on analysis and game equilibrium models, but their analysis and processing ability fall short of our current landscape construction, so BIM modeling is required to construct university landscapes [5].

Since the 21st century, China has entered an era of rapid development, and great progress has been made in economy, industry, and cultural industry. BIM technology was born in 1980s, and with the development of computer hardware and software technology, it gradually showed its systematic 
advantages. BIM refers to the process of dynamically creating, collecting, storing, and managing information in the whole life cycle of a building. Its digital construction method and management concept have been highly praised by the industry and highly valued by the government and have been widely promoted and applied. Some architects even suggested that architects who could not use BIM technology would soon lose their jobs due to lack of competitiveness [6]. BIM (Building Information Modeling) is a relatively new and widely used construction engineering application technology. However, BIM technology is currently limited to information sharing at the architectural level, and the closely related field of campus planning does not fully utilize architectural information, owing to the lack of a research platform at the level of university campus landscape. The use of BIM has been shown to improve the level of informatization and efficiency of project cost management [7]. It can directly calculate the project's cost control, and the time limit for project control can also prepare for an unexpected situation in the future in advance, effectively improving the efficiency of project cost management while also refining project data to ensure the site's construction quality and safety [6]. Despite the fact that the information data contained in BIM series software are rich and comprehensive, information sharing among all participants in the entire life cycle of construction projects is insufficient, and communication efficiency is low, making it impossible to realize information management in the entire life cycle of construction. Furthermore, due to the complex and changing environment of the construction site, as well as the unpredictability of engineering construction, the construction scheme continues to fall short of the requirements for guiding on-site construction, and the use of BIM technology in the construction site is still limited due to the many uncertainties that exist on the construction site, making targeted guidance impossible. Therefore, there are still many problems and challenges in BIM technology [8].

Safety is the most important criterion for all activities, and the goal is to establish a "people-oriented foundation." Safety should ensure all other factors. It is critical to improve the safety of outdoor activity space while providing people with higher quality garden visual beauty. The scientific design of a river landscape can not only provide residents with a relaxing environment with clean air and a wide view but also ensure the river's water supply and purification function, as well as the safety of outdoor activity areas. It jeopardizes the ecological environment's original stability [9]. People are becoming increasingly tired of cold urban buildings, their desire for nature and willingness to get close to nature is deepening, and the problems between urban construction and the natural environment are becoming increasingly complex [10]. With the rapid development of China's economy and the accelerating process of urbanization, people are becoming increasingly tired of cold urban buildings, their desire for nature and willingness to get close to nature is deepening, and the problems between urban construction and the natural environment are becoming increasingly complex. This necessitates the creation of a scientific and reasonable campus environment, combining landscape design ideas of an ecological arrangement by combining the school's cultural geography and campus culture, and finding ways to properly handle the human and natural landscape, so that the university's campus landscape can present a natural sense of harmony [11]. This paper conducts a thorough investigation and investigation of campus landscape security using BIM. The building information model can effectively combine the landscape of the campus with the natural environment.

\section{Related Work}

According to literature [12], this technology can comprehensively monitor the dynamic periodic changes of various indexes and data of construction projects, greatly improving the project's construction efficiency by providing more intuitive and simple construction data and prediction targets for the entire project, effectively reducing construction risks. According to literature [13], despite the fact that modern landscape design in China began late, it is rapidly developing. It has progressed from an early stage of greening with a focus on area to a stage of beautifying with a focus on visual effects, and finally to a new stage of considering place characteristics, integrating diverse contents, and combining ecological concepts. According to literature [14], campus symbiosis and environmental blending should be a constant and core principle that should be considered in design and actively collaborated with to achieve the blending of architecture and landscape. According to literature [15], the visualization of database establishment has been thoroughly studied in the application of GIS technology and the system design of BIM, and the method of visualizing the danger of hazard sources and the results of safety planning has been discussed. [16] Literature A model of urban safety evaluation system composed of nine elements, such as urban disaster, social security, urban fire protection, and ecological environment, was established using the thinking mode of urban disaster science and urban sociology, and the weight of each element was calculated using a statistical method. In literature [17], by integrating BIM and AR technologies, a special system based on Web is proposed to integrate BIM and AR, and it is effectively applied to building quality management (QM). The omission and negligence in the process of building quality are reduced, and the management efficiency is effectively improved. In literature [18], by analyzing the form, elements, and spatial structure of university campus space, the overall design process of university campus is sorted out and summarized. In literature [19], any design form that is coordinated with the ecological process and minimizes its damage to the environment. If ecologism wants to achieve the minimum impact on the environment, even if it is small and inconclusive, it is an inevitable development direction. Literature [20] holds that the construction of campus landscape environment in colleges and universities is a process of growth, a process of combining the characteristics of the times with the historical heritage, not the result of specific planning. The organic growth process of American college campuses expresses the connotation of continuing campus culture, emphasizing the 
combination of old and new buildings and the gradual development. Literature [21] puts forward that the target cost management method should be added into the construction project management system. For the research of cost control and management, foreign countries pay more attention to the control before, during, and after the event, especially the variable cost.

The above literature shows that the university campus landscape is changing day by day throughout the era. People have proposed many methods to optimize the landscape based on BIM, so that BIM can extract and share this information at any time to ensure the construction is completed in a timely manner. According to the information provided by BIM, we can also improve the level of professionals and strengthen department coordination and management at the same time. Assume the true role of BIM in the field of architecture.

\section{Significance and Modeling of Building Information Model for Campus Landscape}

3.1. The Significance of Constructing Campus Landscape on University Campus. The word "campus" is derived from the Latin word campo, which originally meant a well-defined public open field, such as "central square." Later, the term "campus" came to refer to all universities' open spaces, and the central square of the campus became the university's central symbol [22]. The disjointed landscape design of campus buildings has caused the problem of "miscellaneous but not together" from the actual point of view of campus landscape. The landscape image is uneven and fragmented, and the overall feeling of the campus landscape is poor because the landscape is a kind of green after the planned buildings. A small-scale heterogeneous tendency results from the lack of connection between different landscapes; a complete and unified landscape cannot be formed; a smallscale disorder results in the monotony of the campus as a whole; and the campus landscape space lacks rhythm and change.

University campus is a space of special significance. Students on campus gradually form their three views through their study and life here. The university mission of teaching and educating people is invisible. Taking the campus as the carrier, it affects the students' spiritual world. The quality of the campus environment can reflect the academic atmosphere and scientific research level of a school and directly or indirectly affect the quality of education and teaching [23]. The campus architectural landscape should form an organic and unified whole in material, which is reflected in the indispensable and mutual harmony among various environmental elements of the campus under specific space-time conditions. Orderly spatial image, rhythmic and rhythmic change, moderate contrast, and protection of blue and green landscape should be the aesthetic standards of campus landscape architecture integration. Campus culture is the "soul" of campus landscape. Campus landscape should not only build material space landscape but also build social space landscape to meet the needs of campus life and build psychological space landscape to achieve psychological harmony between teachers and students [24]. Campus landscape is a part of urban landscape, and the construction of contemporary university campus landscape is a topic of general concern in society. It should not only meet the functional needs of teachers and students in school but also meet their psychological needs for the landscape environment. The biggest difference between the campus landscape and the park lies in the educational nature of the campus. The campus landscape should emphasize the strong educational consciousness of the campus in order to stimulate students' strong learning motivation. It is also a space with educational significance, use value, and history and culture. A good university campus cannot be separated from the overall planning and design, architectural design, and landscape design.

\subsection{Building Information Model's Information Collection} Model. The safe construction of decoration projects refers to the formulation of the organization plan for safe construction, as well as the work content and functions of the safe implementation of the decoration project, and the implementation plan can be improved according to the implementation effect [25]. In order to analyze the constrained parameters of construction safety management in the life cycle of the university campus landscape, carry out the constrained parameter model of safety management control, realize the safety management construction, and improve the on-site safety management ability. According to the above-mentioned overall design ideas, the design process of the whole life cycle construction safety management is obtained, as shown in Figure 1.

According to the whole life cycle construction safety management control model of university campus landscape shown in Figure 1, to carry out construction safety management, first, BIM information collection is carried out to realize the unified scheduling of manpower, material resources and financial resources in the process of safe construction, and the BIM information collection model is as follows:

$$
\min _{\omega, h, \xi_{l}, \xi_{l}^{*}}=\frac{1}{2} \omega^{T} \omega+c \sum_{i=1}^{l}\left(\xi_{l}+\xi_{l}^{8}\right) .
$$

In the formula, $\xi_{l}$ and $\xi_{l}^{*}$ represent relaxation variables. The descriptive statistical analysis method is used to construct the safety management constraint parameter model of full life cycle construction:

$$
f(x)=\sum_{i=1}^{l}\left(a_{i}+a_{i}^{*}\right) k\left(x-x_{i}\right)+b .
$$

According to the safety management standard of construction project, in the control cycle of the whole life, the acquisition time width of BIM information model is $T=(2 d+1) T_{s}, F_{s}=1 / T_{s}$, let $A=\left\{a_{1}, a_{2}, \ldots, a_{n}\right\}$ be the safety attribute set of construction, $B=\left\{b_{1}, b_{2}, \ldots, b_{m}\right\}$ be the target control subset, $a_{i}$ represent the control gain, $\left\{c_{1}, c_{2}, \ldots, c_{k}\right\}$ represent the BIM statistical sequence, and adopt the random game control method [7]. The 


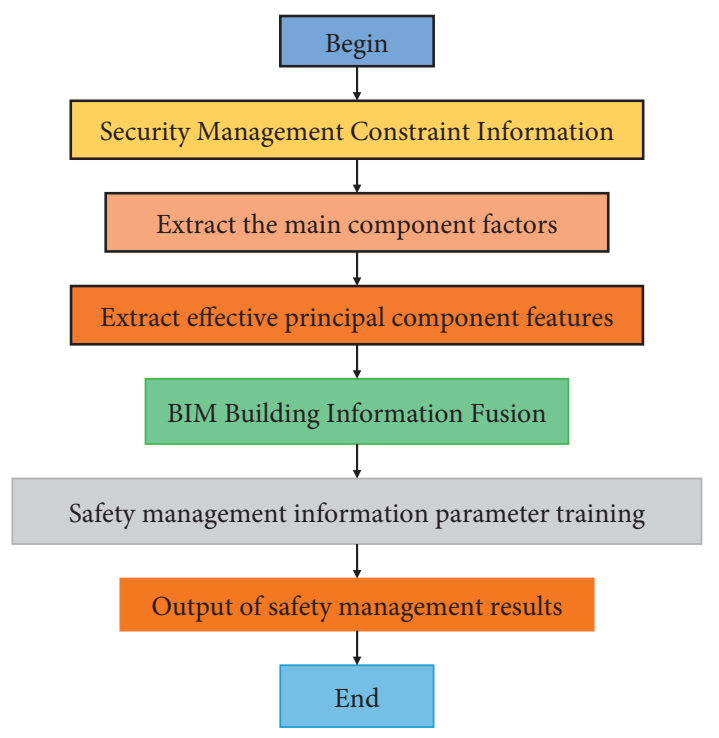

Figure 1: The design process of campus landscape life cycle construction safety management.

management equilibrium scheduling model of safe construction is obtained as follows:

$$
\begin{gathered}
\operatorname{BIM}(B)=-\sum_{i=1}^{m} p_{i} \times \log _{2} p_{i}, \\
\operatorname{BIM}_{A}(B)=\sum_{j=1}^{u} \frac{\left|B_{j}\right|}{|B|} \times \operatorname{BIM}\left(B_{J}\right), \\
\operatorname{Gain}(A)=\operatorname{BIM}(B)-\mathrm{BIM}_{A}(B) .
\end{gathered}
$$

Among them, $B_{j}$ represents the safety input control parameters. For the characteristic components containing attributes, $a_{x}$ uses the random information fusion method to obtain the university campus landscape construction safety control index set with the output gain of gain (a).

The completion of the main building is the foundation of the building decoration model. If the model fails to meet the quality requirements, it will result in a mismatch between the collected data and the entity, as well as a mismatch between the reserved space of the building entity and the design drawings, among other things. As a result, using BIM to create a decorative model is critical. The importance of construction safety cannot be overstated. On the one hand, it has a significant impact on constructors' life safety; on the other hand, it harms the economic benefits and reputation of construction companies, and even has a negative impact on their future development planning [26]. When it comes to the use of BIM technology in site planning for construction projects, BIM emphasizes the collaborative role of policies, processes, and technologies throughout the project life cycle in order to achieve data sharing and collaboration. Figure 2 depicts risk management optimization.

BIM technology can help realize the safety management of decoration project construction. Project implementation is an overall process, not just composed of one part, each stage is closely related, and the participation of each stage can constitute the final whole, so the implementation and management of the project need to consider the whole from the overall perspective [27]. In the safety management of construction projects, the establishment of a BIM technical model containing a large amount of safety information on the construction site can effectively identify the dangerous factors in the construction, so as to quickly find the source of the hazard, such as temporary protective devices and safe passages established during the construction. It is marked in the BIM technical model, and the level of danger can be set at the same time. The construction safety management model of building engineering is shown in Figure 3.

Let the safety management personnel of the project plan the construction site layout of each important node in the process of project construction, the operation arrangement of large machinery and vehicles, and the measure layout scheme before the construction starts, so as to find problems in advance and formulate corresponding improvement schemes for optimization [28]. Therefore, on the basis of BIM, the security model of university campus landscape is optimized, and the hierarchical management method is adopted to carry out sectional inspection of security information management, and the inspection statistics are obtained:

$$
U(Q)=\sum_{i=1}^{N} Q_{i} e_{i}-\frac{1}{2}\left(\sum_{i=1}^{N} Q_{i}^{2}+2 \rho \sum_{i \neq j} Q_{i} Q_{j}\right)-\sum_{i=1}^{N} P_{i} Q_{i},
$$

where $Q=\left(Q_{1}, \ldots, Q_{i}, \ldots, Q_{M}\right)$ is the contribution intensity of $m$ safety management control nodes, under BIM constraint parameters, combined with statistical quantitative regression analysis, the statistical regression analysis model of safety management model is obtained as follows:

$$
\begin{gathered}
u(S)=\max _{X} u^{T} X, \\
A X \leq g(S), \\
X \geq 0 .
\end{gathered}
$$

According to the above mathematical modeling, the whole life cycle construction of university campus landscape is realized.

\section{Result Analysis and Discussion}

The corresponding construction engineering safety problem has become the focus of increasing attention as China's construction industry has grown rapidly. Safety accidents will inevitably have a significant impact on people's lives and businesses, resulting in personal injury and financial loss. There are significant potential safety hazards in the construction process due to the unique characteristics of the construction industry, such as poor working conditions, noncentralized operations, mobile operations, and long construction periods. As a result, construction safety has become a major concern in the industry. Second, the construction industry is rapidly developing due to the rapid growth of the building economy, but construction safety management is not keeping up with the pace of 


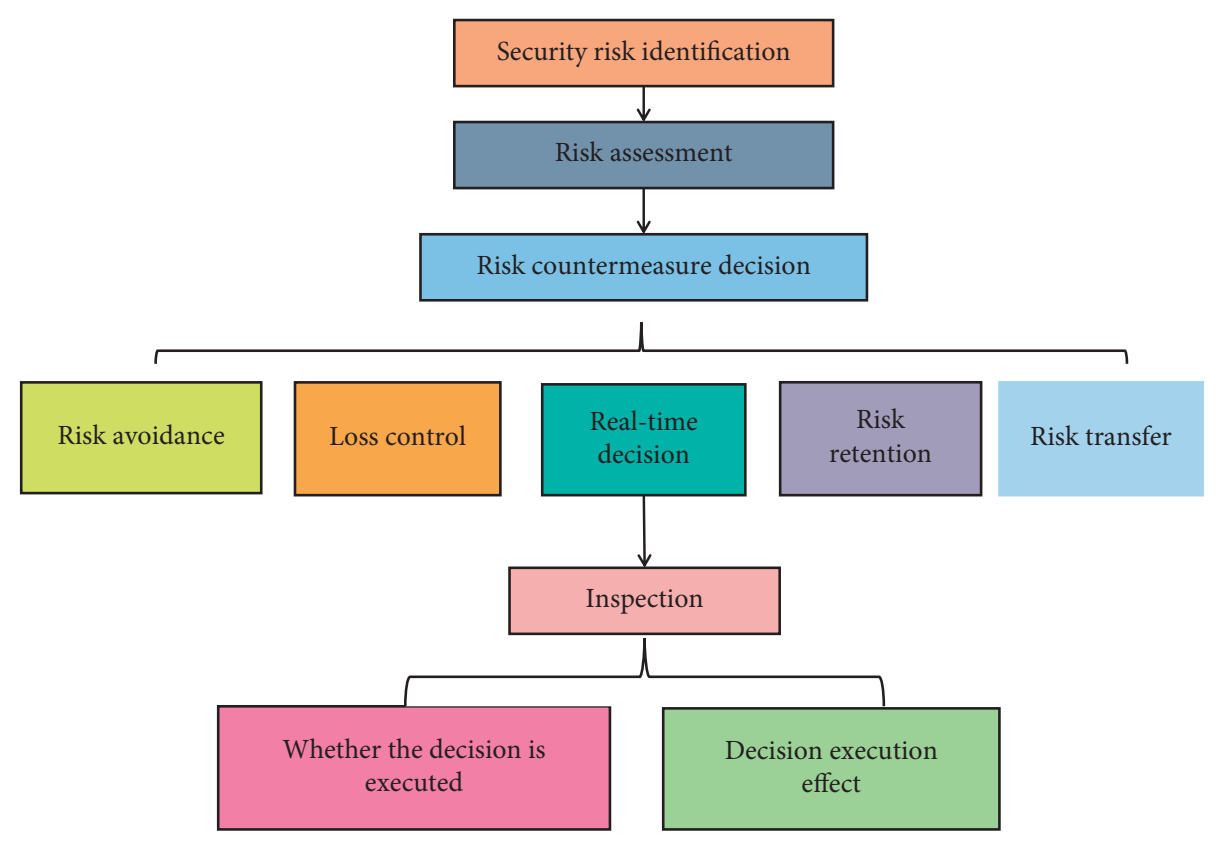

FIGURE 2: Security risk management optimization diagram.

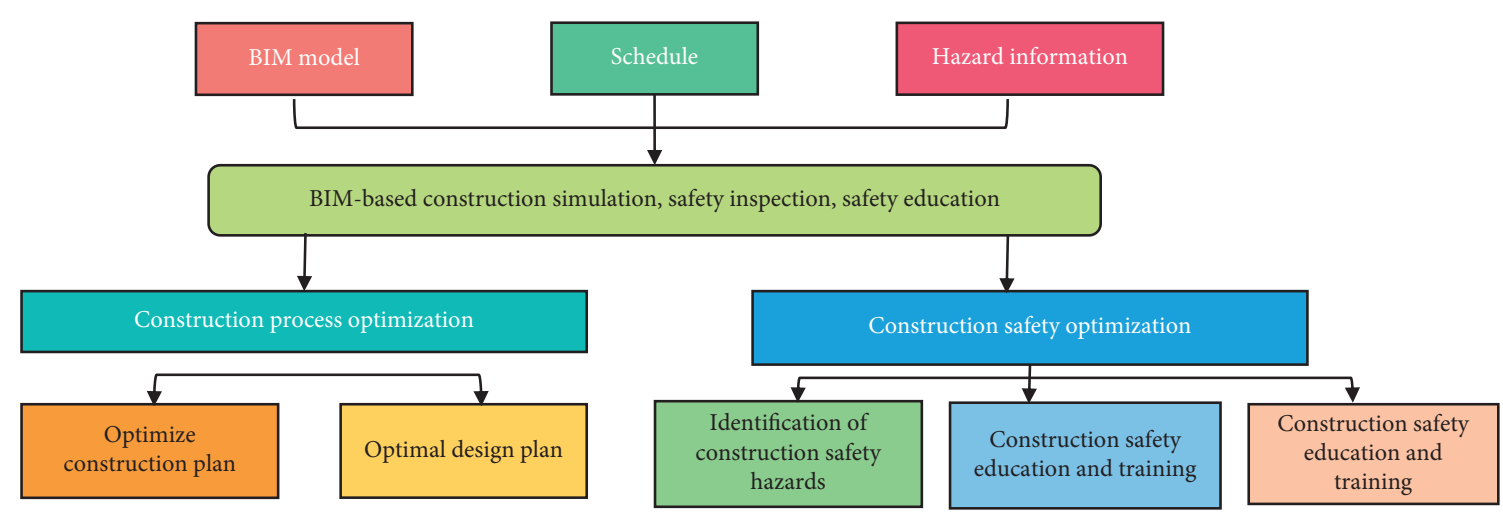

FIGURE 3: Construction safety management model diagram of building engineering.

development, and the current safety management model is unable to meet the needs of the current development situation [29]. It obstructs the construction industry's longterm development and makes China's overall construction situation bleak. The construction safety accidents in the national construction industry are shown in Figure 4.

Security is an eternal topic in human survival and social progress, the cornerstone of every industry and the premise of every work. Without security, economic and social benefits cannot be discussed. Especially in the construction industry, the hidden dangers of building safety often cause important accidents. Traditional building methods have limitations on buildings and cannot be very predictable. There is an urgent need for a scientific and effective safety management method and means to implement systematic and modern management of engineering projects. As a new auxiliary application means of construction project management, BIM technology also adds convenient services for safety management. Therefore, it is inevitable that BIM will replace the traditional architectural style. Building safety is not only the image and needs of enterprises but also the guarantee for constructors and future buildings. BIM can well foresee the problems in building management and can make optimization plans to avoid accidents; connect the information of safety management and other aspects of enterprise management and build a video monitoring system, so as to improve the efficiency of safety inspection and monitoring. The accident comparison diagram of traditional building accidents and BIM buildings is shown in Figure 5.

The rule of integrating architectural design with nature has become increasingly important as a result of industrialization and information technology. The landscape on campus is no exception. In order to meet the needs of development, all schools construct large-scale campuses. Schools have built new campuses in various locations in addition to reconstructing the original campus. This setting offers a plethora of practical opportunities for campus landscape design. We can only make a qualitative leap in 


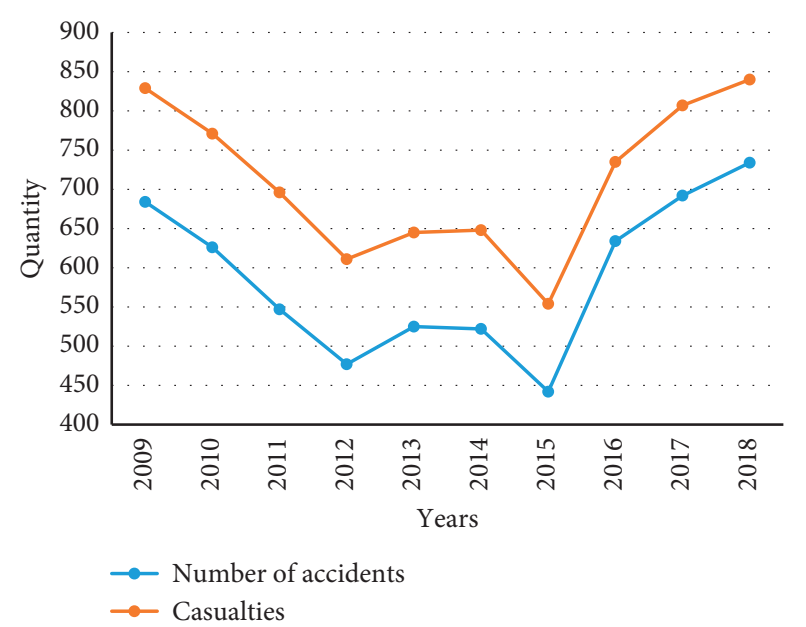

FIgURE 4: National construction safety accident map.

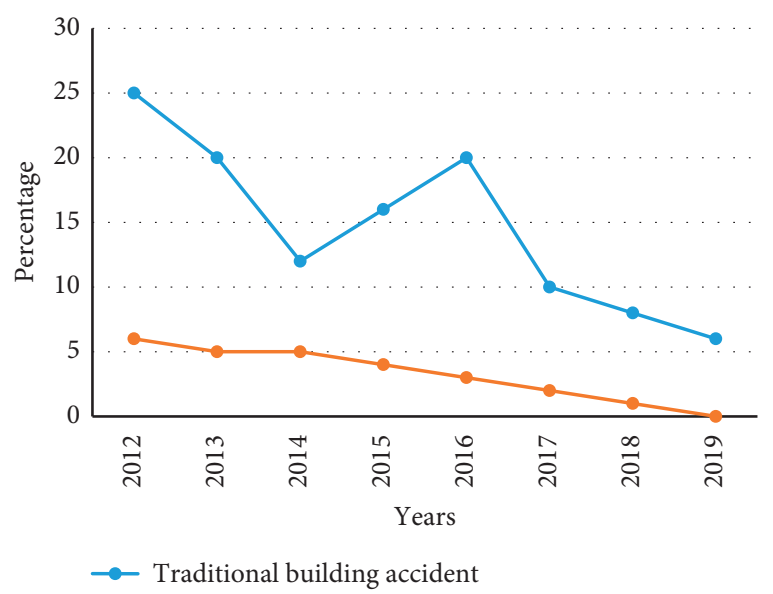

FIGURE 5: Comparison of traditional buildings and BIM building accidents.

campus environment by including landscape in campus planning and architecture and integrating campus architecture and landscape together. More and more campuses are beginning to design their campuses with the overall architecture and landscape in mind. Landscape design is involved in the planning and architectural design of a beautiful landscape. The current university discipline inspection commission places a high value on the campus landscape. It gradually has the functional characteristics of education and communication and gradually becomes the main activity place for students and teachers to communicate and learn, as educational ideas and methods change, school buildings improve, and architectural functions change. As a result, campus landscape architecture, indoor and outdoor design, and planning and layout have a significant impact on the campus staircase environment and the school's cultural atmosphere. The emergence of the Internet of Things, the Internet, big data, and other technologies, as well as the rapid advancement of science and technology, have changed our previous lifestyles and ideas, ushering us into the information age. It has brought subversive reforms to the construction industry's development, and BIM offers a new perspective on the campus landscape. The comparison of attention between traditional buildings and BIM buildings is shown in Figure 6.

In order to test the performance of this model in realizing the construction safety management and control of the university campus landscape throughout the life cycle, tests were carried out. The management objects are people, funds, materials, and field equipment. The fuzzy closeness coefficient is 0.24 , which is set according to the above parameters, test the gains of different models for overall construction management, and use the method in this paper to improve the control performance of safety management. The results of the test with good safety management performance are shown in Figure 7.

Figure 8 is a broken stone diagram based on BIM database modeling and analysis. The abscissa of broken stone diagram is the number of components of factors, and the ordinate is the value of characteristic values. From the diagram, it can be intuitively observed that the characteristic values of the first five factors are greater than 1 , and the presented lines are steep. From the sixth factor, the characteristic values of variables are less than 1 , and the curve begins to become more gentle. Therefore, it can be judged that the inflection point of broken stone diagram is actually at the fifth factor, which means that when extracting the common factor, it is extracted. This can effectively reduce the time of traditional detection, and the location of modeling can be directly selected according to the basis of BIM modeling, which also shows that BIM has the decisionmaking ability, and can directly reduce the dimension of multivariate variables through modeling, and integrate the original complex variables into several core factors. Realize the appearance, material, technology, and spatial relationship of the building in a real and vivid way, which is convenient for architects to make efficient and accurate judgments and provide decision-making basis for the reliability and feasibility of the previous scheme.

Because the energy consumption and solid waste disposal of buildings in the construction process emit a significant amount of greenhouse gases, accurately estimating the carbon emissions of buildings in the construction process is critical for achieving low-carbon development. In this paper, a BIM platform for carbon emission measurement is built using BIM technology and the carbon emission theory in the building construction process, and the carbon emission in the construction process is measured using the carbon emission coefficient, providing a scientific basis and theoretical support for the development of low-carbon buildings and environmental management. The carbon emissions calculated by BIM model are shown in Figure 9 .

Combining the BIM model to calculate carbon emissions is more convenient and controllable than traditional calculation methods. Since the planning and design of the building directly affects the selection and later use of building materials, if BIM is applied in the initial stage of design, a BIM model is established to measure carbon emissions, and the building materials and equipment systems are replaced according to carbon emissions, and the 


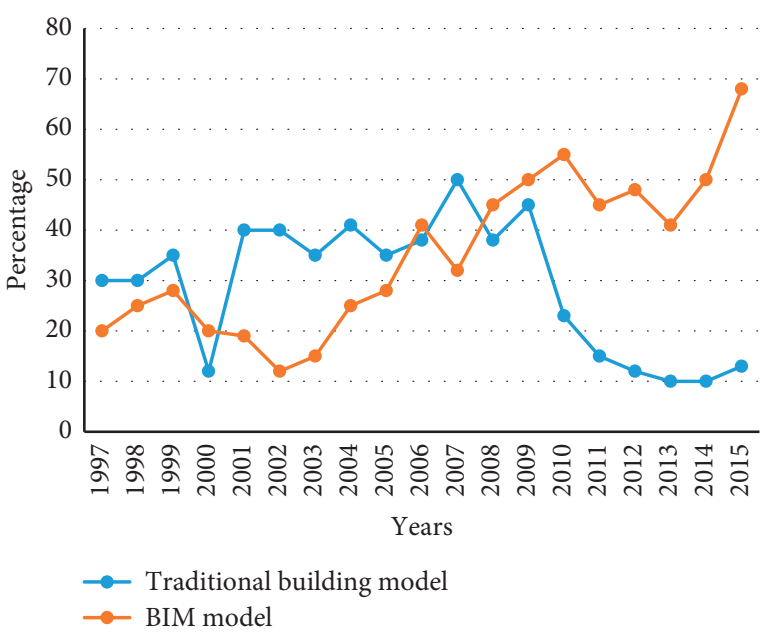

FIGURE 6: Comparison of attention between traditional architecture and BIM architecture.

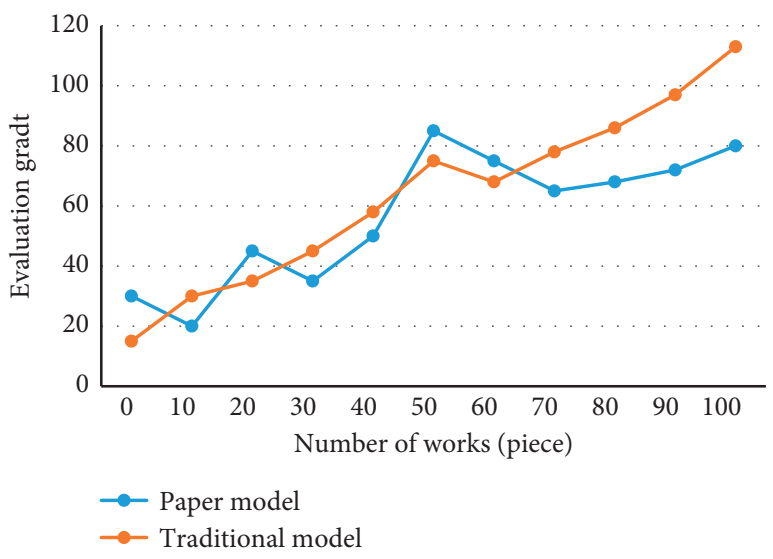

FIGURE 7: Security management performance test.

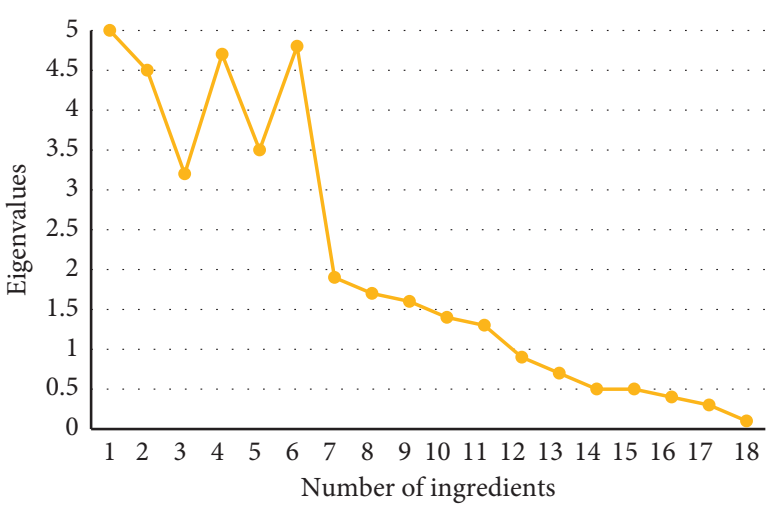

FIgURE 8: Crushed stone diagram in BIM state.

lowest carbon and environmentally friendly design is selected. The program can effectively reduce carbon emissions at all stages of the life cycle.

BIM technology has incomparable advantages in the informatization of water cost management compared to

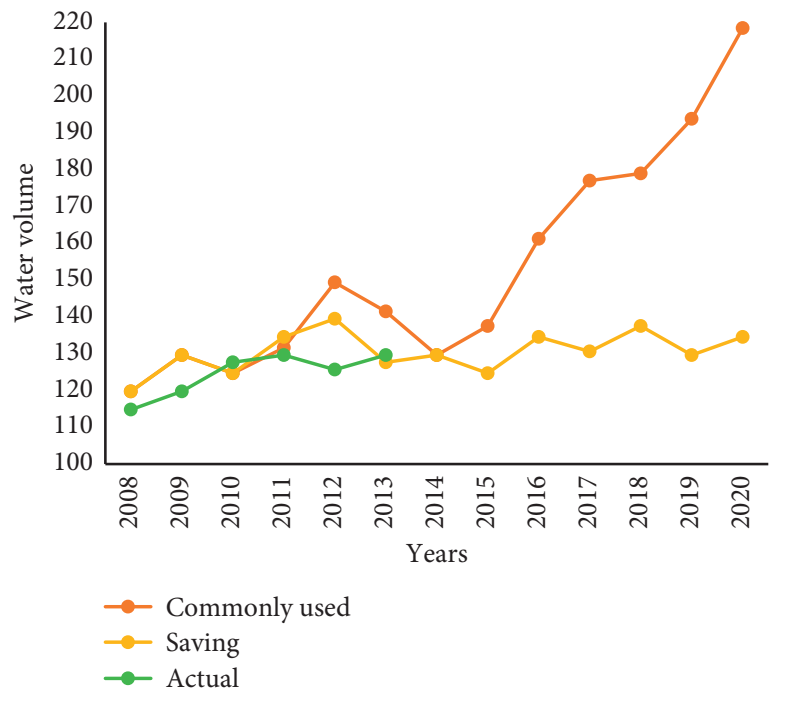

FIGURE 9: BIM model calculation of carbon emissions.

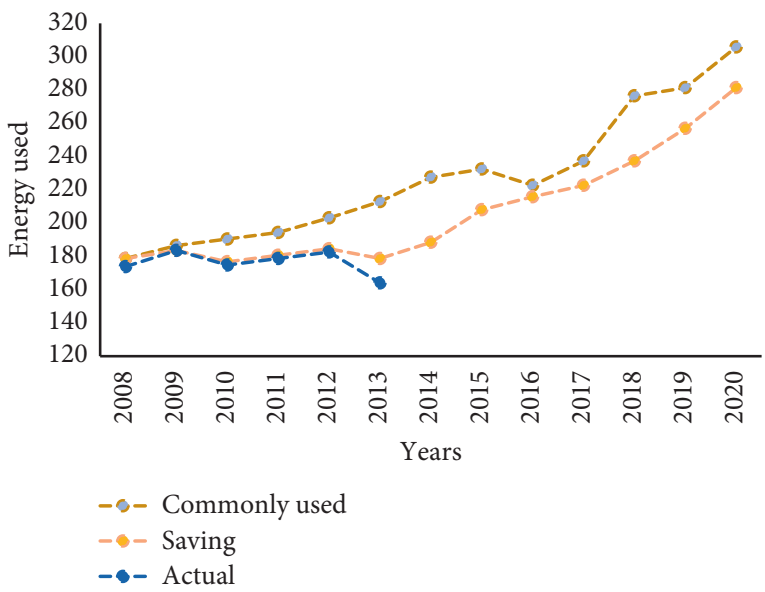

FIGURE 10: BIM model calculation of electricity consumption.

traditional technologies because water costs have large value, individuality, dynamics, hierarchy, and compatibility. First, it greatly improves the efficiency and accuracy of cost work, establishes a three-dimensional model through BIM technology to automatically identify various components, quickly transfers the calculated engineering quantity, captures the dynamic structural design in time, effectively avoids missing items (BIM work) and miscalculations, and improves the accuracy of bill pricing work; and second, it greatly improves the efficiency and accuracy of bill pricing work. Second, the model collision inspection tool, which is based on BIM technology, is used to optimize the scheme and eliminate process pipeline conflicts. The cost engineer can work with the designers to compare and optimize the process and scheme from a cost control standpoint, allowing them to effectively control design changes and reduce project costs. The electricity consumption calculated by BIM model is shown in Figure 10. 


\section{Conclusions}

A complete understanding of the idea of campus landscape environment design includes three aspects. First, we should meet the requirements of campus use and develop the potential of land. Second, the campus environment is a place for teachers and students to rest. It is an ecological area full of leisure, peace, and quiet. Third, design a landscape that provides aesthetic enjoyment. The introduction of security theory into the landscape design of university campus can guide the design to develop in a more effective, reasonable, and scientific direction, refine the concept of security design, so as to better improve the overall landscape image of campus environment, meet the physiological and psychological needs of teachers and students, and better serve the public.The application of BIM technology in the safety management of campus landscape construction engineering can play a great role in site planning, hazard identification, safety monitoring, education, and training, so as to effectively improve the safety management level of construction engineering. Safety management is a very important content in the management of construction industry. Construction enterprises should be aware of the importance of safety management. The model constructed by BIM technology has prominent advantages in the safe construction of decoration projects and realizes the informatization of decoration industry. The safe construction of decoration projects will develop rapidly under the guidance of BIM technology. Aiming at the application of BIM in university campus landscape architecture, this paper makes mathematical modeling, uses data to effectively avoid risks, combines humanities and nature, improves the quality and speed of the project, and saves industrial costs. Because of time, there are still deficiencies in the course, and follow-up research will be continued in the later stage.

\section{Data Availability}

The data used to support the findings of this study are available from the corresponding author upon request.

\section{Conflicts of Interest}

The author does not have any possible conflicts of interest.

\section{Acknowledgments}

This study was supported by Scientific research project of Education Department of Shaanxi Province Research on campus security Environment Design based on CPTED Theory-the study of Xi 'an area project number :20JK0418.

\section{References}

[1] Z. Zhu, Y. Zhang, and L. Cui, "Design and implementation of a large-scale architectural landscape 3D simulation system based on BIM technology," Modern Electronic Technology, vol. 40, no. 4, p. 5, 2017.

[2] S. Chen, J. Ding, and Y. Jiang, "Application of lianhua bridge BIM technology and study on mechanical properties of special-shaped pylons," Journal of Chongqing Jianzhu University: Natural Science Edition, vol. 39, no. 10, p. 6, 2020.

[3] F. Jiang and M. Wu, "Design and implementation of a shared street landscape reconstruction simulation system based on BIM technology," Modern Electronic Technology, vol. 43, no. 3, p. 5, 2020.

[4] S. Fan and H. Cheng, "Landscape aesthetic design and implementation of xinjin baihe bridge," Highway, no. 5, p. 4, 2019.

[5] D. Zhou, "Research on the construction safety management model of the full life cycle of university campus landscape based on BIM," Automation and Instrumentation, no. 2, p. 4, 2019.

[6] J. Tu, Y. Wang, and C. Liu, "The deepening design method of urban landscape university campus landscape based on BIM," Journal of Engineering Management, vol. 33, no. 4, pp. 71-75, 2019.

[7] X. Yang, W. Sun, and J. Dong, "Research on the safety early warning system of construction workers falling from heights based on cloud-BIM," Science and Technology Management Research, vol. 40, no. 7, p. 7, 2020.

[8] X. Ning, W. Yang, and B. Yang, "Research on rapid modeling technology of complex university campus landscape structure based on CATIA[J]," Special Structure, vol. 34, no. 6, p. 6, 2017.

[9] H. Sun, "Research on the application of BIM technology in the safety evaluation of highway projects," Highway, vol. 63, no. 6, p. 4, 2018.

[10] J. Zhou, "Based on the advantages and application of BIM technology in the safety construction of decoration projects," The Journal of Adhesion, vol. 44, no. 10, p. 4, 2020.

[11] L. Zhang, W. Liu, and W. Zhang, "Research on key technologies of engineering construction safety based on BIM," Construction Economics, no. 8, p. 6, 2018.

[12] Y. Chen and H. Shan, "Research on early warning and realtime control of underground engineering construction safety risk based on BIM and Internet of Things," Bulletin of Science and Technology, vol. 32, no. 7, p. 5, 2016.

[13] H. Hao, "Research on college campus landscape detection and security evaluation system based on BIM," Automation and Instrumentation, no. 12, p. 3, 2016.

[14] Y. Cui, G. Shi, and Z. Sun, "Application of BIM technology in the implementation of safe and civilized housing construction standardization[J]," China Coal Geology, vol. 31, no. S02, p. 3, 2019.

[15] E. Kang and J. Wang, "Research on the safety technology of smart mine engineering based on BIM," Metal Mine, no. 4, p. 6, 2021.

[16] M. Tang, Y. Wang, and Z. Qiu, "Design of a multi-dimensional early warning system for highway safety based on BIM," Microcomputer Applications, vol. 37, no. 7, p. 4, 2021.

[17] Y. Huang, J. She, and Y. Song, "Security risk automatic identification system based on BIM-Ontology from the perspective of security design," Journal of Civil Engineering and Management, vol. 38, no. 5, p. 8, 2021.

[18] X. Song, "Research on intelligent management of engineering construction safety based on BIM," Construction Economy, vol. 42, no. 2, p. 3, 2021.

[19] X. Hu, Y. Pan, Y. Zhu, J. Chen, K. Su, and X. Wang, "Construction of a visual platform for structural safety monitoring of power transmission systems based on BIM+WebGIS," China Rural Water and Hydropower, no. 12, p. 5, 2020.

[20] Q. Shi, Y. Pang, and Y. Jiang, "Building construction safety risk early warning decision model simulation based on system 
dynamics and BIM," Journal of Civil Engineering and Management, vol. 33, no. 2, p. 7, 2016.

[21] S. Zhang, Z. Zhao, and Z. Xia, "The application of BIM technology in the sponge landscape of primary school campus," Journal of Henan Institute of Science and Technology: Natural Science Edition, vol. 49, no. 3, p. 10, 2021.

[22] M. Wang, J. Liu, and G. Yuan, "Virtual campus construction solution design in a new technology environment," Digital User, vol. 25, no. 2, pp. 34-35, 2019.

[23] Q. Chen and X. Wang, The Application of BIM in the Direction of Environmental Design Professional Landscape-CTake the Garland Software as an Example, First Issue, no. 9, p. 2, New Campus, 2017.

[24] H. Yan, "Landscape and terrain BIM modeling practice of west lake university," Shanghai Construction Technology, no. 5, p. 3, 2021.

[25] L. Xu, "Research on the application of BIM technology in the teaching of environmental art design in colleges and universities," Art Technology, vol. 31, no. 2, p. 1, 2018.

[26] X. Ye, "On the landscape design of university campus," Modern Horticulture, no. 24, p. 1, 2013.

[27] Y. He, "Interpretation of the cultural features of peking university campus landscape," Architectural Design Management, no. 12, p. 3, 2013.

[28] $\mathrm{H}$. Xing, $\mathrm{X}$. Wu, and $\mathrm{Y}$. Wu, "Research on college campus landscape design based on low-impact concepts," Journal of Jiangsu Institute of Architecture and Technology, vol. 17, no. 3, pp. 32-35, 2017.

[29] Y. Zhou, S. Li, and Zhou, "The application of "spiritual place" concept in modern college campus landscape design," Journal of Anhui Agricultural Sciences, vol. 45, no. 27, p. 3, 2017. 